\title{
Strong ground motion in the Kathmandu Valley during the 2015 Gorkha, Nepal, earthquake
}

\author{
Nobuo Takai ${ }^{1 *}$, Michiko Shigefuji ${ }^{2}$, Sudhir Rajaure ${ }^{3}$, Subeg Bijukchhen ${ }^{4}$, Masayoshi Ichiyanagi², \\ Megh Raj Dhital ${ }^{5}$ and Tsutomu Sasatani ${ }^{6}$
}

\begin{abstract}
On 25 April 2015, a large earthquake of Mw 7.8 occurred along the Main Himalayan Thrust fault in central Nepal. It was caused by a collision of the Indian Plate beneath the Eurasian Plate. The epicenter was near the Gorkha region, $80 \mathrm{~km}$ northwest of Kathmandu, and the rupture propagated toward east from the epicentral region passing through the sediment-filled Kathmandu Valley. This event resulted in over 8000 fatalities, mostly in Kathmandu and the adjacent districts. We succeeded in observing strong ground motions at our four observation sites (one rock site and three sedimentary sites) in the Kathmandu Valley during this devastating earthquake. While the observed peak ground acceleration values were smaller than the predicted ones that were derived from the use of a ground motion prediction equation, the observed peak ground velocity values were slightly larger than the predicted ones. The ground velocities observed at the rock site (KTP) showed a simple velocity pulse, resulting in monotonic-step displacements associated with the permanent tectonic offset. The vertical ground velocities observed at the sedimentary sites had the same pulse motions that were observed at the rock site. In contrast, the horizontal ground velocities as well as accelerations observed at three sedimentary sites showed long duration with conspicuous long-period oscillations, due to the valley response. The horizontal valley response was characterized by large amplification (about 10) and prolonged oscillations. However, the predominant period and envelope shape of their oscillations differed from site to site, indicating a complicated basin structure. Finally, on the basis of the velocity response spectra, we show that the horizontal long-period oscillations on the sedimentary sites had enough destructive power to damage high-rise buildings with natural periods of 3 to $5 \mathrm{~s}$.
\end{abstract}

Keywords: 2015 Gorkha Nepal earthquake, Kathmandu Valley, Strong ground motion, Velocity pulse motion, Valley response

\section{Introduction}

The Himalayan mountain range formed by the collision of the Indian and Eurasian plates is regarded as an earthquake prone zone. The Indian Plate underthrusts the Eurasian Plate in this region, and a number of large earthquakes have occurred in the Himalayas. Kathmandu, the capital city of Nepal, is located in the Kathmandu Valley. The valley is surrounded by mountains on all sides and is filled with soft lake sediments of Plio-Pleistocene origin (Dhital 2015); the thickness of the sediments is

\footnotetext{
* Correspondence: tki@eng.hokudai.ac.jp

${ }^{1}$ Faculty of Engineering, Hokkaido University, Kita 13, Nishi 8, Kita-ku,

Sapporo, Japan

Full list of author information is available at the end of the article
}

more than $650 \mathrm{~m}$ in the central part of the valley (Moribayashi and Maruo 1980). Large earthquakes in the past have caused significant damage in the Kathmandu Valley; for example, during the 1934 Nepal-Bihar earthquake ( $M w$ 8.2), nearly $19 \%$ of the buildings were destroyed inside the valley and more than 8000 people from all over the country lost their lives (Dixit et al. 2013). The principal factor associated with the significant damage is considered to have been the responses of soft lake sediments during seismic motion. Considering these tectonic and site conditions within the Kathmandu Valley, we have established four strong-motion array observation stations (one rock site and three sedimentary sites) in
Springer

(C) 2016 Takai et al. Open Access This article is distributed under the terms of the Creative Commons Attribution 4.0 International License (http://creativecommons.org/licenses/by/4.0/), which permits unrestricted use, distribution, and reproduction in any medium, provided you give appropriate credit to the original author(s) and the source, provide a link to the Creative Commons license, and indicate if changes were made. 
the valley to understand the site effects of the Kathmandu Valley to strong ground motion. These sites were established on 20 September 2011.

On 25 April 2015, a large Mw 7.8 earthquake occurred along the Himalayan front (USGS 2015a). This event had a low-angle thrust faulting mechanism and an 8.2$\mathrm{km}$ hypocentral depth (USGS 2015a). The epicenter was near the Gorkha region, $80 \mathrm{~km}$ northwest of the Kathmandu Valley, and the rupture propagated eastward from the epicentral region passing through the Kathmandu Valley (e.g., Avouac et al. 2015; Fan and Shearer 2015; Galetzka et al. 2015; Grandin et al. 2015; Hayes et al. 2015; Kobayashi et al. 2015; Yagi and Okuwaki 2015). This event resulted in over 8000 fatalities, which occurred mostly in Kathmandu and in adjacent districts (MoHA 2015). Although the earthquake vulnerability of Kathmandu was considerably serious, there were only two official seismometers recording earthquakes on the sedimentary sites: KATNP by USGS (2015b) and DMG (Bhattarai et al. 2015). We succeeded in observing strong ground motions at our array sites in the Kathmandu Valley during this devastating earthquake. In this letter, we describe the characteristics of the ground motions observed in the Kathmandu Valley and perform a simple examination of the long-period valley response in the frequency domain. Finally, we discuss the velocity response spectra for the horizontal ground motions. Data used in this letter include the ground motions observed by the Faculty of Engineering, Hokkaido University in collaboration with the Central Department of Geology, Tribhuvan University, Nepal, and also those observed by some other organizations (Galetzka et al. 2015; USGS 2015b).

\section{Strong-motion array observations in the Kathmandu Valley}

Accelerometers have been installed at the following four sites along a straight (west to east) profile in the Kathmandu Valley: KTP (Kirtipur Municipality Office, Kirtipur), TVU (Central Department of Geology, Tribhuvan University, Kirtipur), PTN (Pulchowk Campus, Institute of Engineering, Tribhuvan University, Patan), and THM (University Grants Commission Office, Sanothimi, Bhaktapur). The site locations are shown in Fig. 1a. We collected data using highly damped moving coil type (dimensionless damping constant $h \sim 26$, natural frequency of $3 \mathrm{~Hz}$ ) Mitsutoyo JEP-6A3-2 accelerometers (Kudo et al. 2002) and Hakusan DATAMARK LS-8800 data loggers at a sampling rate of $100 \mathrm{~Hz}$. The data loggers can perform GPS time calibration. Due to long hours of power outage in Kathmandu, the observation system is powered by chargeable batteries and voltage stabilizers for smooth operation. The accelerometer has a flat response $(-3 \mathrm{~dB})$ of ground acceleration from

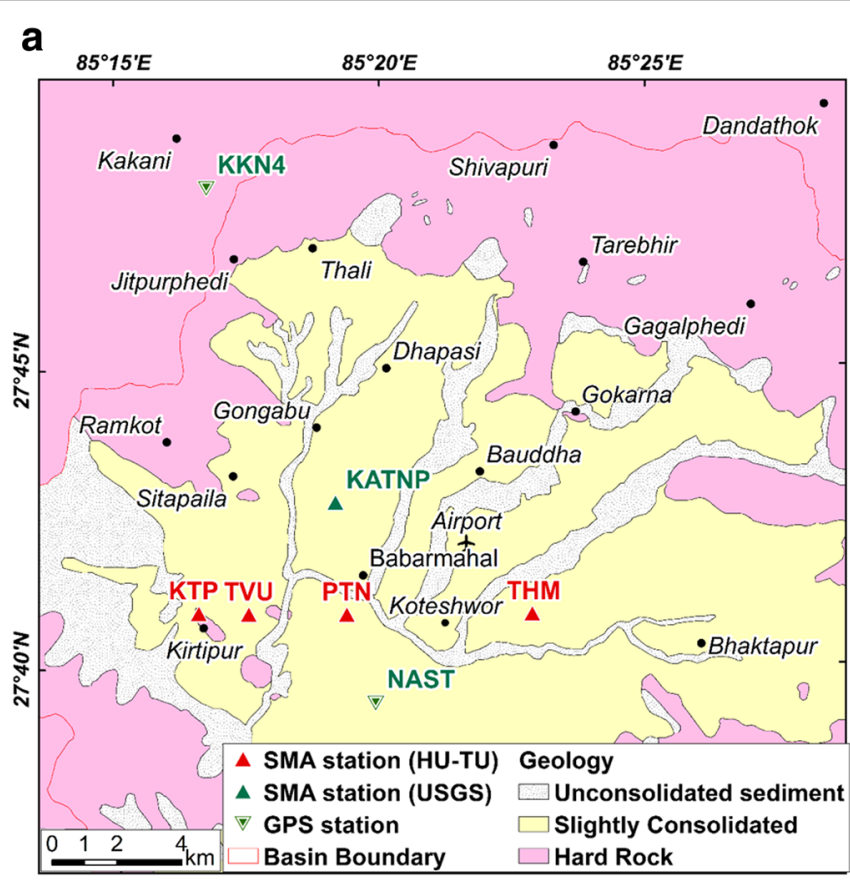

b

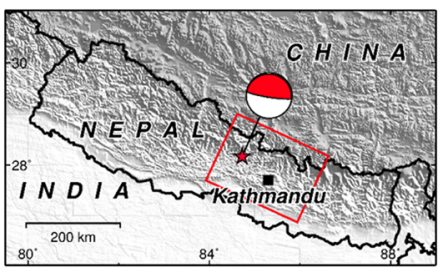

$-1$

Fig. 1 Location map. a Observation sites in the Kathmandu Valley with geological formations (modified from Shrestha et al. 1998). Strong-motion accelerometer (SMA) stations are divided into HU-TU (Hokkaido University and Tribhuvan University; red) and USGS sites (green). The GPS stations were used in Galetzka et al. (2015). b The epicenter of the 2015 Gorkha earthquake is shown by the red star. The fault plane shown with the red rectangular and the focal mechanism are estimated by USGS (2015a) 
$0.1 \mathrm{~Hz}$ to an aliasing frequency (Kudo et al. 2002). It is necessary to apply a correction of the sensor-response to the observed records in order to derive accurate ground motions (Kudo et al. 2002). We installed these instruments on the first floor of reinforced concrete buildings that were one- to four-stories high, and the accelerometers were fixed to the floor with bolts. We have recorded data continuously at the four sites for over 2 years. We had observed and analyzed the data from a few moderate-size earthquakes (Bijukchhen et al. 2015) during 2 years' observations before the 2015 Gorkha earthquake.

The shallow subsurface S-wave velocities of the observation sites were investigated by the surface wave method during installation of accelerometers (Takai et al. 2015). The tested velocity of $\mathrm{S}$-wave at a depth of $10 \mathrm{~m}$ was over $700 \mathrm{~m} / \mathrm{s}$ at the KTP site, but it was less than $200 \mathrm{~m} / \mathrm{s}$ at the other three sites. These velocities are consistent with the geological formations; KTP is located on a rock and TVU, PTN, and THM are located on lake sediments in the valley (Fig. 1a).

\section{Ground accelerations}

The fault size of the 2015 Gorkha earthquake estimated by USGS (2015a) was about $200 \mathrm{~km}$ long and $150 \mathrm{~km}$ wide (Fig. 1b), and it was associated with a large slip area near the Kathmandu Valley. During data processing, we first made a baseline correction by removing the mean determined from a segment of the pre-event part of the original record from the entire original acceleration record. Next, we made the sensor-response correction by using the FFT deconvolution filter. The accelerograms obtained after applying the sensor-response correction are shown in Fig. 2 along with those from the KATNP (Kanti Path, Kathmandu) station, which is managed by United States Geological Survey (USGS) (the records of KATNP lack absolute timing).

The largest peak ground acceleration (PGA, $241 \mathrm{~cm} / \mathrm{s}^{2}$ ) was recorded on the EW component at the rock site KTP, and the peak amplitude of the horizontal components was $250 \mathrm{~cm} / \mathrm{s}^{2}$ at this station. This large PGA was due to isolated short-period waves at about $30 \mathrm{~s}$ from the origin time. The horizontal PGA values were compared with those predicted by two ground motion prediction equations (GMPEs) for ground accelerations. We found that the observed PGA values were smaller than those estimated by the GMPEs ( $\mathrm{Si}$ and Midorikawa 1999; Boore et al. 2014). Anderson et al. (1986) pointed out that the observed PGA values above the source area during the 1985 Michoacan, Mexico, earthquake (Mw 8.0) were considerably smaller (PGA, $100-200 \mathrm{~cm} / \mathrm{s}^{2}$ ) than those during the 1985 Valparaiso, Chile, earthquake ( $\mathrm{Mw}$ 8.0). This may indicate that the Mexico and Chile subduction zones are different from each other in terms of the nature of the interplate coupling as discussed by Houston and Kanamori (1986). The nature of interplate coupling at the Nepal collision zone on the other hand has to be studied in detail.

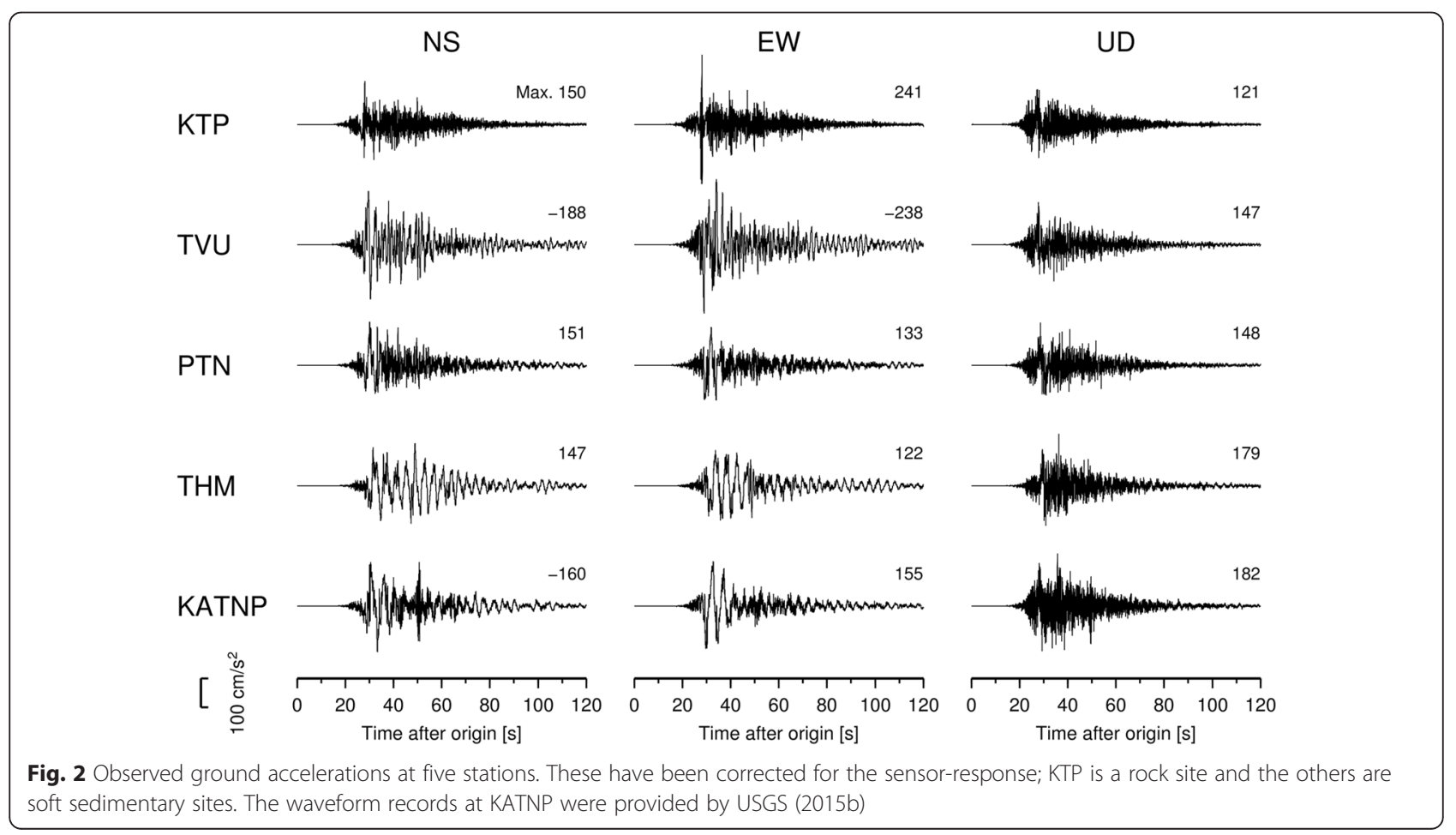


The horizontal accelerograms at the sedimentary sites had long duration with conspicuous long-period oscillations; however, the envelopes of oscillations in waveforms differed from site to site. Conversely, the vertical accelerograms at all the sites were nearly the same and were associated with no long-period oscillations. These observations are characterized by the site effects of the Kathmandu Valley, that is, the valley response. Conspicuous long-period accelerations were also observed within the lake zone in Mexico City during the 1985 Michoacan earthquake (Mw 8.0) (Anderson et al. 1986). The PGA values at both locations were comparable, while the predominant periods were somewhat different; specifically, the periods in the Kathmandu Valley were 3 to 5 s (see Figs. 3 and 4), while those in Mexico City were 2 to $3 \mathrm{~s}$. We should note that although both the conspicuous long-period accelerations represent an effect of the lake sediments under the valleys, the exciting mechanisms may have been different because the fault distance of the Kathmandu Valley was about $10 \mathrm{~km}$, whereas the relevant distance in Mexico City was about $300 \mathrm{~km}$; therefore, the incoming wave fields into the two valleys were different from each other. It is well known that the long-period accelerations caused the collapse of, or severe damage to, many tall buildings in the lake zone in Mexico City (Anderson et al. 1986). Fortunately, in the case of the Gorkha earthquake, there were no high-rise or base-isolated buildings with the long natural period in and around the Kathmandu Valley.
The original array data are provided as Additional files $1,2,3$, and 4 .

\section{Ground velocities}

We derived the velocity waveforms by integrating the sensor-response corrected accelerograms with a linear acceleration method in the time domain (Fig. 3). The highest peak ground velocity (PGV, $99 \mathrm{~cm} / \mathrm{s}$ ) was given by the NS component record at TVU, and the peak amplitude of the horizontal components was $108 \mathrm{~cm} / \mathrm{s}$ at this station. We then compared the observed PGV values with those predicted by the GMPEs in the same manner as that for the PGA values. While the observed PGA values were smaller than the predicted ones, the observed PGV values were slightly larger than the predicted ones.

The velocity waveforms on the NS and UD components observed at the rock site KTP displayed the typical velocity pulse ground motions; the arrival time of the velocity pulses roughly corresponded to the S-wave arrival time from the hypocenter. They showed a singlesided velocity pulse with a width of about $6 \mathrm{~s}$, while the EW component showed a double-sided pulse with a period of about $10 \mathrm{~s}$. The ground velocities at KKN4 obtained from the high-rate (5-Hz sampling) GPS record (Galetzka et al. 2015) had waveforms similar to those observed at KTP, while the amplitudes of the KKN4 velocity pulses were about 1.4 times larger than those of the KTP velocity pulses; KKN4 is a rock site in Kakani located northwest of Kathmandu as shown in Fig. 1. The

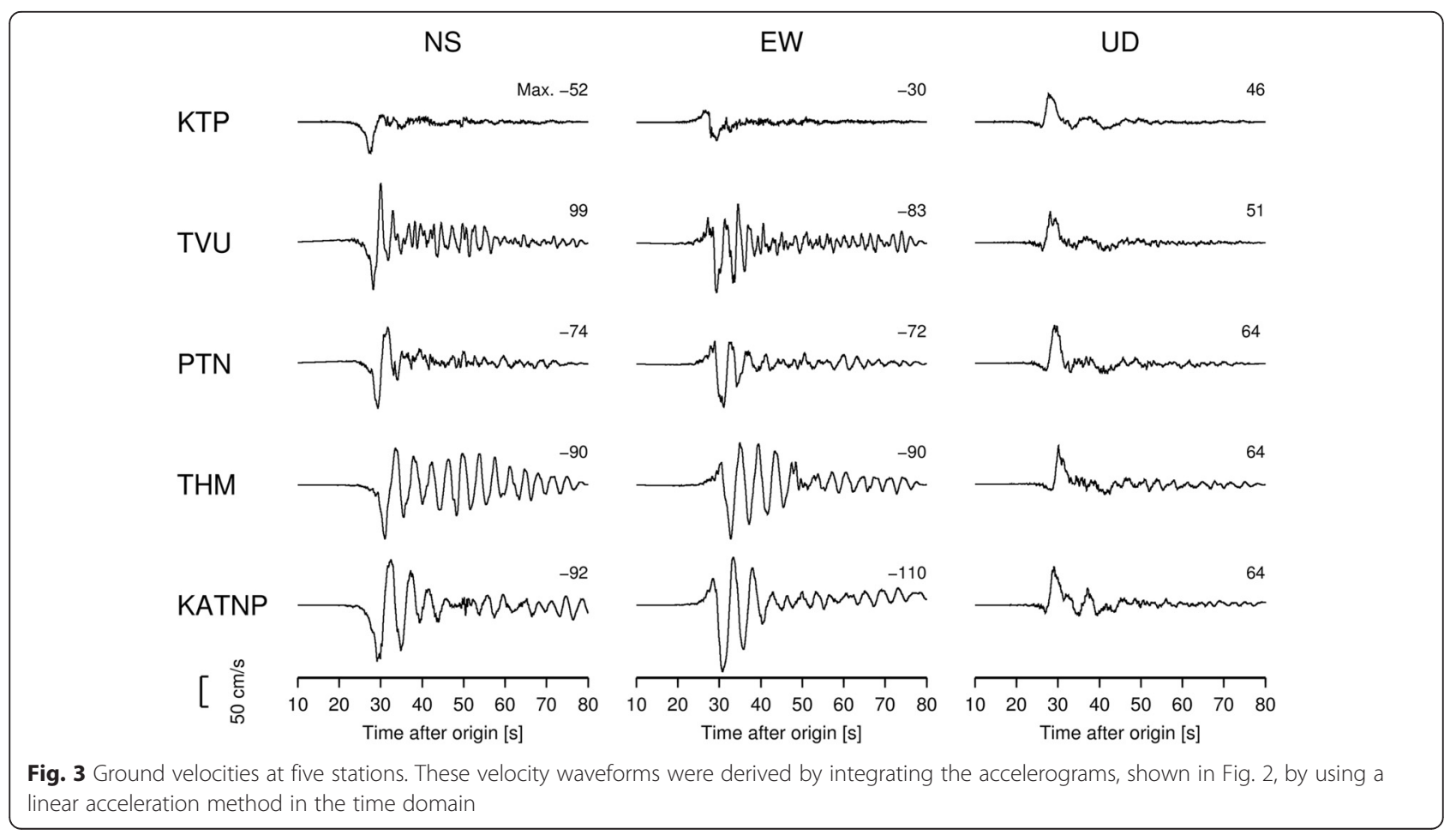



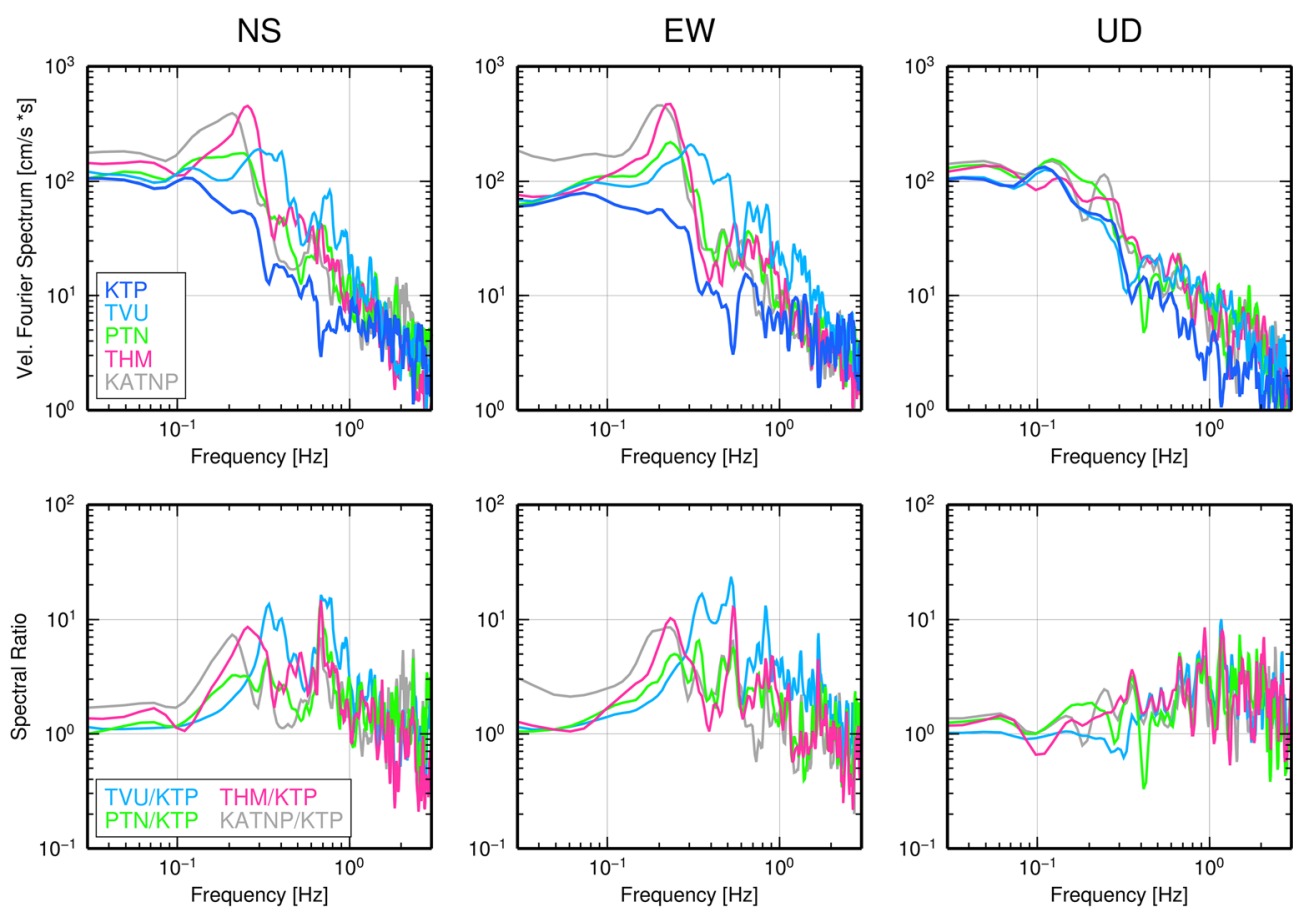

Fig. 4 Fourier amplitude spectra and spectral ratios. The Fourier amplitude spectra of the ground velocities shown in Fig. 3 (upper panel). The ratios of amplitude spectra at the sedimentary sites to those at station KTP (lower panel)

velocity pulse and pulse-like ground motions observed near surface of the faults can be considered to be the effect of the forward rupture directivity or the tectonic offset (e.g., Loh et al. 2000; Mavroeidis and Papageorgiou 2003; Hisada and Bielak 2003; Baker 2007; Dreger et al. 2011). The Kathmandu Valley is located at a very close distance $(\sim 10 \mathrm{~km})$ from the rupture area, and large slip areas likely exist near the valley (Galetzka et al. 2015). Furthermore, the displacement waveforms derived from the velocity pulses showed a monotonic step, as shown in Fig. 5. These facts demonstrate that the observed velocity pulses were the result of static displacement for the tectonic offset.

The UD component ground velocities at the sedimentary sites were nearly the same as those observed at the

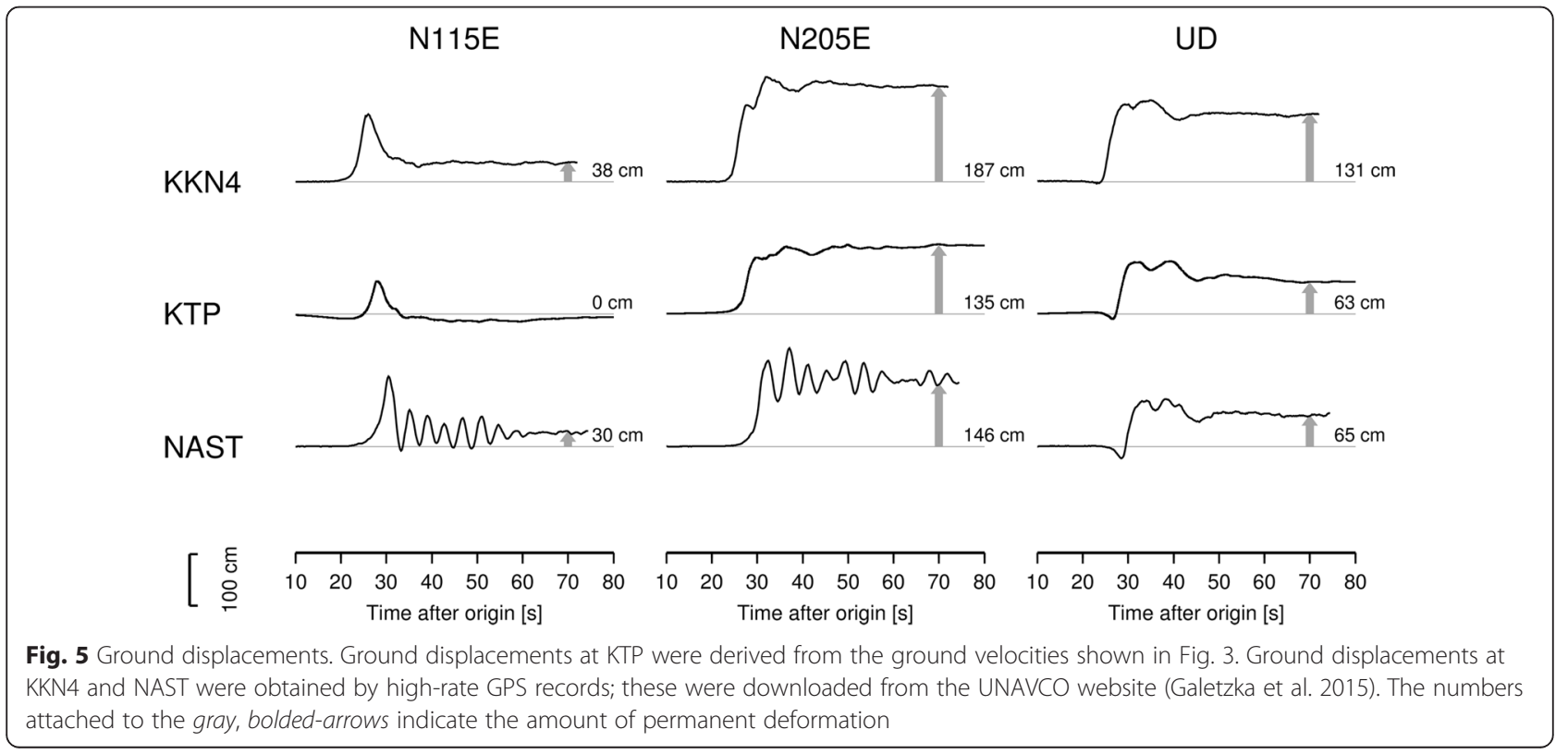


rock site KTP. In contrast, the horizontal ground velocities at the sedimentary sites had long duration with conspicuous long-period oscillations; we pointed out these features for the accelerograms discussed in the previous section (Fig. 2). Assuming that the KTP (rock site) ground velocities represent incoming wave fields into the Kathmandu Valley, we can consider the large ground velocities at the sedimentary sites in Fig. 3 to be the long-period (3-5 s) valley response. Here, we perform a simple examination of the long-period valley response in the frequency domain. The upper panel in Fig. 4 displays the Fourier amplitude spectra of the ground velocities shown in Fig. 3; we classified the spectra into three components in order to compare one another's spectral shape for a given component. The lower panel in Fig. 4 shows the Fourier amplitude spectral ratios of the sedimentary site spectra to the rock site spectrum for each component; these figures correspond to the valley response in the frequency domain for a given site. From examination of Figs. 3 and 4, we found that the longperiod valley response had the following features: (1) the horizontal valley response was characterized by large amplification (about 10) and prolonged oscillations, (2) the predominant period and envelope shape of the horizontal oscillation differed not only from site to site but also between the NS and EW components at a given site, and (3) the vertical valley response had no amplification and no prolonged oscillations. These features demonstrate that the long-period valley response of the Kathmandu Valley is considerably complicated, because they cannot be understood with one-dimensional seismic wave amplification. Previous studies indicated an uneven basement topography of the valley with many undulations (Moribayashi and Maruo 1980; Paudyal et al. 2013) which may result in a complicated response. In order to understand the factors involved in the observed longperiod valley response of the Kathmandu Valley, we will have to clarify the three-dimensional underground structure of the valley in addition to the dense strong-motion observations in and around the valley.

\section{Ground displacements}

The ground velocities at KTP where the simple velocity pulses were observed on the UD and NS components were integrated to derive the displacement waveforms. The KTP displacement waveforms are shown in Fig. 5, together with those observed by the high-rate GPSs at KKN4 and NAST (Khumaltar, Lalitpur) (Galetzka et al. 2015); these locations are shown in Fig. 1. Here, the horizontal components were rotated to the fault-normal (N205E) and fault-parallel (N115E) directions based on the USGS fault model (USGS 2015a) in order to obtain a reasonable interpretation of the Earth's surface motion. The derived displacements at KTP were characterized by a monotonic step (also including the contributions of dynamic phases) on the fault-normal and UD components. They showed permanent displacements of $135 \mathrm{~cm}$ in the fault-normal direction and $63 \mathrm{~cm}$ in the upward direction (the vector sum was $149 \mathrm{~cm}$ ), while there was a negligible permanent displacement in the fault-parallel direction. The displacement waveforms at KTP were similar to those at the rock site KKN4 for the three components. However, their permanent deformation values were different; the values at KKN4 were larger than those at KTP because the KKN4 site was closer to the large slip area (Galetzka et al. 2015). The UD displacement and permanent deformation at the sedimentary site NAST were similar to those at KTP. However, the horizontal displacement waveforms at NAST were different from those at KTP; the long-period oscillations observed at NAST resulted from the valley response as mentioned in the previous section. In spite of the contamination by the valley response, the horizontal permanent deformation values at NAST did not greatly differ from those at KTP; the distance between NAST and KTP was only $6 \mathrm{~km}$. These pieces of evidence indicate that the displacement waveforms at KTP derived from the accelerograms produced reliable motion for the Earth's surface.

Conversely, the ground displacements derived from the accelerograms at our sedimentary sites and KATNP showed different waveforms than those of KTP. Although the UD displacements had similar waveforms and permanent deformations as those at the rock site KTP, the horizontal displacements showed considerable drifts. According to Boore (2001), the source of the drifts was likely the shift in the zero level due to tilting (either dynamic or permanent) in the instruments; however, the effect of tilt on the vertical components was much smaller. These observations demonstrate that the highrate GPS waveforms captured the ground displacements better than the horizontal accelerograms at the sedimentary sites where the horizontal long-period ground motions were largely amplified, as shown in Fig. 3.

\section{Horizontal velocity response spectra}

Finally, to discuss the destructive power of observed strong ground motions for buildings, we calculated horizontal velocity response spectra $(h=0.05)$; the horizontal response spectrum was obtained based on the maximum of the vector sum of the two horizontal-component response histories for a specific natural period. Figure 6 shows the horizontal velocity response spectra for the five sites in the Kathmandu Valley. In this figure, the two notable response spectra TKT (Takatori, Kobe, Japan) and TCU068 (Shigang District, Taichung, Taiwan) are also shown; these were derived from records observed at the near-surface fault. The ground velocity at TKT 


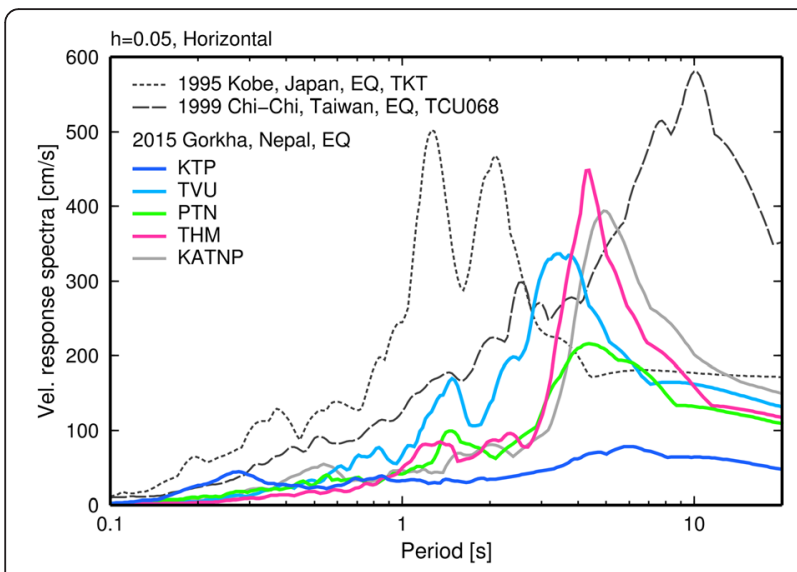

Fig. 6 Horizontal velocity response spectra. The horizontal velocity response spectra for five sites in the Kathmandu Valley and two notable sites (TCU068 and TKT); these horizontal response spectra were obtained based on the maximum of the vector sum of the two horizontal-component response histories for a specific natural period by using the damping factor $h=0.05$. The TCU068 and TKT records were downloaded from CESMD

showed pulse-like motion with a large PGV of $161 \mathrm{~cm} / \mathrm{s}$ during the 1995 Kobe earthquake in Japan; the pulse-like motion was caused by the directivity effect (Kamae and Irikura 1998). The ground velocity at TCU068 showed a velocity pulse with a large PGV of $400 \mathrm{~cm} / \mathrm{s}$ and a long pulse width of $8 \mathrm{~s}$ during the $1999 \mathrm{Chi}$-Chi earthquake in Taiwan; the velocity pulse was caused by fling-step motion (Bolt and Abrahamson 2003). These records are frequently used for building structure assessments of pulse motion (e.g., Hall et al. 1995; Kalkan and Kunnath 2006).

First, we compare the two response spectra for KTP and TCU068, which were derived from the velocity pulses. The TCU068 spectrum had a large peak at a period of $10 \mathrm{~s}$, which was several times larger than the KTP peak at $6 \mathrm{~s}$; this was due to the difference in amplitude and width of the two pulses. The spectral peaks for the sedimentary sites (TVU, PTN, THM, and KATNP) were considerably larger than that for the rock site KTP in the period range of 3 to $5 \mathrm{~s}$. Furthermore, we should point out that these peaks, except for the one at PTN, were larger than the two notable response spectra in the period range of 3 to $5 \mathrm{~s}$. These were due to the longperiod valley response, as mentioned in the previous section. In general, we may conclude that the horizontal ground motions at the sedimentary sites had enough destructive power to damage high-rise buildings which have natural periods of 3 to $5 \mathrm{~s}$.

\section{Concluding remarks}

Since the capital city of Kathmandu in Nepal is located on a sediment-filled valley and was located at a very close distance to the fault plane of the 2015 Gorkha earthquake, a wealth of new information on strong ground motions was captured there. At the rock sites, simple velocity pulses were observed on the NS and UD components; these were the result of the tectonic offset. At the sedimentary sites, although velocity pulses were also observed on the vertical component, the horizontal ground velocities showed largely amplified and prolonged long-period oscillations compared with the rock site motions; these resulted from the valley response. Finally, we found that the horizontal long-period oscillations had enough destructive power to damage high-rise buildings. It will be important for us to understand the factors involved in the long-period valley response observed in the Kathmandu Valley based on the three-dimensional velocity structure of the valley in future studies.

\section{Additional files}

Additional file 1: KTP001504250611.dat. Strong motion acceleration data at KTP station. (DAT $606 \mathrm{~kb}$ )

Additional file 2: TVU001504250611.dat. Strong motion acceleration data at TVU station. (DAT $606 \mathrm{~kb}$ )

Additional file 3: PTN001504250611.dat. Strong motion acceleration data at PTN station. (DAT 606 kb)

Additional file 4: THM001504250611.dat. Strong motion acceleration data at THM station. (DAT $606 \mathrm{~kb}$ )

\section{Competing interests}

The authors declare that they have no competing interests.

\section{Authors' contributions}

NT, MS and TS designed this study. MS and SB analyzed the data. NT and TS drafted the manuscript. All authors contributed equally toward managing the observations. All authors read and approved the final manuscript.

\section{Acknowledgements}

The KATNP record was provided by USGS (USGS 2015b). TCU068 (Lee et al. 2001) and TKT (Nakamura et al. 1996) records were downloaded from the Center for Engineering Strong Motion Data (CESMD) at http://www.strongmotioncenter.org/ (accessed 20 October 2015). The KKN4 and NAST data were obtained from the UNAVCO website (Galetzka et al. 2015). This study was partly supported by the Grant-in-Aid for Scientific Research (Nos. 23404005 and 15H05793) from the JSPS (Japanese Society for the Promotion of Science) and the MEXT (Ministry of Education, Culture, Sports, Science, and Technology) of Japan, the Heiwa Nakajima Foundation, the Obayashi Foundation, the MEXT program entitled Japan's Earthquake and Volcano Hazards Observation and Research Program, and the Japan Science and Technology (JST) agency's J-RAPID Program. Our grateful thanks to Dr. Y. Dhakal, S. Ghimire, Messrs. K. Sawada, H. Okajima, Y. Miyahara, and M. Aoki for their assistance. We used the Generic Mapping Tools (Wessel and Smith 1991) for drawing portions of the figures.

\section{Author details}

${ }^{1}$ Faculty of Engineering, Hokkaido University, Kita 13, Nishi 8, Kita-ku, Sapporo, Japan. ${ }^{2}$ Institute of Seismology and Volcanology, Faculty of Science, Hokkaido University, Kita 10, Nishi 8, Kita-ku, Sapporo, Japan. ${ }^{3}$ Department of Mines and Geology, Lainchour, Kathmandu, Nepal. ${ }^{4}$ Graduate School of Engineering, Hokkaido University, Kita 13, Nishi 8, Kita-ku, Sapporo, Japan. ${ }^{5}$ Central Department of Geology, Tribhuvan University, Kirtipur, Kathmandu, Nepal. ${ }^{6}$ Ainosato 1-4-19-12 Kita-ku, Sapporo, Japan.

Received: 26 October 2015 Accepted: 6 January 2016 Published: 26 January 2016 


\section{References}

Anderson JG, Bodin P, Brune JN, Prince J, Singh SK, Quaas R, Onate M (1986) Strong ground motion from the Michoacan, Mexico, earthquake. Science 233(4768):1043-1049

Avouac J-P, Meng L, Wei S, Wang T, Ampuero J-P (2015) Lower edge of locked Main Himalayan Thrust unzipped by the 2015 Gorkha earthquake. Nat Geosci 8(9):708-711. doi:10.1038/ngeo2518

Baker JW (2007) Quantitative classification of near-fault ground motions using wavelet analysis. Bull Seismol Soc Am 97(5):1486-1501. doi:10.1785/0120060255

Bhattarai M, Adhikari LB, Gautam UP, Laurendeau A, Labonne C, Hoste-Colomer R, Sèbe O, Hernandez B (2015) Overview of the large 25 April 2015 Gorkha, Nepal, earthquake from accelerometric perspectives. Seismol Res Lett 86(6): 1540-1548. doi:10.1785/0220150140

Bijukchhen S, Takai N, Shigefuji M, Ichiyanagi M, Sasatani T, Rajaure S, Dhital MR (2015) A comparative study of strong ground motion records from 30 August 2013 south Tibet earthquake on the rock and soil sites of Kathmandu valley. Journal of Nepal Geological Society 48:48-48

Bolt B, Abrahamson N (2003) Estimation of strong seismic ground motions. In: Lee WHK, Kanamori H, Jennings P, Kisslinger C (eds) International Handbook of Earthquake \& Engineering Seismology. vol 2. Elsevier Science, New York, pp 983-1001

Boore DM (2001) Effect of baseline corrections on displacements and response spectra for several recordings of the 1999 Chi-Chi, Taiwan, earthquake. Bull Seismol Soc Am 91(5):1199-1211. doi:10.1785/0120000703

Boore DM, Stewart JP, Seyhan E, Atkinson GM (2014) NGA-West2 equations for predicting PGA, PGV, and $5 \%$ damped PSA for shallow crustal earthquakes. Earthq Spectra 30(3):1057-1085. doi:10.1193/070113EQS184M

Dhital MR (2015) Geology of the Nepal Himalaya, 1st edn. Springer International Publishing, Switzerland. doi:10.1007/978-3-319-02496-7

Dixit AM, Yatabe R, Dahal RK, Bhandary NP (2013) Initiatives for earthquake disaster risk management in the Kathmandu valley. Nat Hazards 69(1):631-654. doi:10.1007/s11069-013-0732-9

Dreger D, Hurtado G, Chopra A, Larsen S (2011) Near-field across-fault seismic ground motions. Bull Seismol Soc Am 101(1):202-221. doi:10.1785/0120090271

Fan WY, Shearer PM (2015) Detailed rupture imaging of the 25 April 2015 Nepal earthquake using teleseismic P waves. Geophys Res Lett 42(14):5744-5752. doi:10.1002/2015gl064587

Galetzka J, Melgar D, Genrich JF, Geng J, Owen S, Lindsey EO, Xu X, Bock Y, Avouac J-P, Adhikari LB, Upreti BN, Pratt-Sitaula B, Bhattarai TN, Sitaula BP, Moore A, Hudnut KW, Szeliga W, Normandeau J, Fend M, Flouzat M, Bollinger L, Shrestha P, Koirala B, Gautam U, Bhatterai M, Gupta R, Kandel T, Timsina C, Sapkota SN, Rajaure S, Maharjan N (2015) Slip pulse and resonance of the Kathmandu basin during the 2015 Gorkha earthquake, Nepal. Science 349(6252):1091-1095. doi:10.1126/science.aac6383

Grandin R, Vallée M, Satriano C, Lacassin R, Klinger Y, Simoes M, Bollinger L (2015) Rupture process of the Mw = 7.9 2015 Gorkha earthquake (Nepal): insights into Himalayan megathrust segmentation. Geophys Res Lett 42(20):8373-8382 doi:10.1002/2015GL066044

Hall JF, Heaton TH, Halling MW, Wald DJ (1995) Near-source ground motion and its effects on flexible buildings. Earthq Spectra 11(4):569-605. doi:10.1193/1.1585828

Hayes GP, Briggs RW, Barnhart WD, Yeck WL, McNamara DE, Wald DJ, Nealy JL, Benz HM, Gold RD, Jaiswal KS, Marano K, Earle PS, Hearne MG, Smoczyk GM, Wald LA, Samsonov SV (2015) Rapid characterization of the 2015 Mw 7.8 Gorkha, nepal, earthquake sequence and its seismotectonic context. Seismol Res Lett 86(6):1557-1567. doi:10.1785/0220150145

Hisada Y, Bielak J (2003) A theoretical method for computing near-fault ground motions in layered half-spaces considering static offset due to surface faulting, with a physical interpretation of fling step and rupture directivity. Bull Seismol Soc Am 93(3):1154-1168. doi:10.1785/0120020165

Houston H, Kanamori H (1986) Source characteristics of the 1985 Michoacan, Mexico earthquake at periods of 1 to 30 seconds. Geophys Res Lett 13(6): 597-600. doi:10.1029/GL013i006p00597

Kalkan E, Kunnath SK (2006) Effects of fling step and forward directivity on seismic response of buildings. Earthq Spectra 22(2):367-390. doi:10.1193/1.2192560

Kamae K, Irikura K (1998) Source model of the 1995 Hyogo-Ken Nanbu earthquake and simulation of near-source ground motion. Bull Seismol Soc Am 88(2):400-412

Kobayashi T, Morishita Y, Yarai H (2015) Detailed crustal deformation and fault rupture of the 2015 Gorkha earthquake, Nepal, revealed from ScanSAR-based interferograms of ALOS-2. Earth Planets Space 67(1):201
Kudo K, Kanno T, Okada H, Özel O, Erdik M, Sasatani T, Higashi S, Takahashi M, Yoshida K (2002) Site-specific issues for strong ground motions during the Kocaeli, Turkey, earthquake of 17 August 1999, as inferred from array observations of microtremors and aftershocks. Bull Seismol Soc Am 92(1): 448-465. doi:10.1785/0120000812

Lee WHK, Shin TC, Kuo KW, Chen KC, Wu CF (2001) CWB free-field strong-motion data from the 9-21-1999 Chi-Chi earthquake, digital acceleration files on CDROM. Seismology Center, Central Weather Bureau, Taipei, Taiwan, publication version 9 January 2001, Vol. 1

Loh C-H, Lee Z-K, Wu T-C, Peng S-Y (2000) Ground motion characteristics of the Chi-Chi earthquake of 21 September 1999. Earthq Eng Struct D 29(6):867-897. doi:10.1002/(SICI) 1096-9845(200006)29:6<867::AID-EQE943>3.0.CO;2-E

Mavroeidis GP, Papageorgiou AS (2003) A mathematical representation of near-fault ground motions. Bull Seismol Soc Am 93(3):1099-1131. doi:10.1785/0120020100

MoHA (2015) The Ministry of Home Affairs (MoHA) Government of Nepal: Nepal Earthquake 2015: Disaster Recovery and Reconstruction Information Platform (NDRRIP). http://drrportal.gov.np/ndrrip/main.html. Accessed OCT 202015

Moribayashi S, Maruo Y (1980) Basement topography of the Kathmandu Valley, Nepal: an application of gravitational method to the survey of a tectonic basin in the Himalayas. Journal of the Japan Society of Engineering Geology 21(2):80-87. doi:10.5110/jjseg.21.80

Nakamura Y, Uehan F, Inoue H (1996) Waveform and its analysis of the 1995 Hyogo-Ken-Nanbu Earthquake (II). JR Earthquake Information No 23d, Railway Technical Research Institute, Tokyo (in Japanese)

Paudyal YR, Yatabe R, Bhandary NP, Dahal RK (2013) Basement topography of the Kathmandu Basin using microtremor observation. J Asian Earth Sci 62:627-637, http://dx.doi.org/10.1016/j.jseaes.2012.11.011

Shrestha O, Koirala A, Karmacharya S, Pradhananga U, Pradhan P, Karmacharya R (1998) Engineering and environmental geological map of the Kathmandu valley. Department of Mines and Geology, Kathmandu

Si H, Midorikawa S (1999) New attenuation relationships for peak ground acceleration and velocity considering effects of fault type and site condition. Journal of structural and construction engineering 523:63-70 (in Japanese with English abstract)

Takai N, Sawada K, Shigefuji M, Bijukchhen S, Ichiyanagi M, Sasatani T, Dhakal P, Rajaure S, Dhital MR (2015) Shallow underground structure of strong ground motion observation sites in the Kathmandu valley. Journal of Nepal Geological Society 48:50-50

USGS (2015a) M7.8 - 36 km E of Khudi, Nepal. http://earthquake.usgs.gov/earthquakes/ eventpage/us20002926\#scientific_finitefault:us_us20002926. Accessed SEP20 2015

USGS (2015b) NetQuakes:Station KATNP_NQ_01, 25 April 2015. http://earthquake.usgs. gov/monitoring/netquakes/station/KATNP_NQ_01/20150425061138/. Accessed SEP20 2015

Wessel P, Smith WHF (1991) Free software helps map and display data. Eos, Trans Amer Geophys Union 72(41):441-441. doi:10.1029/90eo00319

Yagi Y, Okuwaki R (2015) Integrated seismic source model of the 2015 Gorkha, Nepal, earthquake. Geophys Res Lett 42(15):2015GL064995. doi:10.1002/2015GL064995

\section{Submit your manuscript to a SpringerOpen ${ }^{\circ}$ journal and benefit from:}

- Convenient online submission

- Rigorous peer review

- Immediate publication on acceptance

- Open access: articles freely available online

- High visibility within the field

- Retaining the copyright to your article

Submit your next manuscript at $>$ springeropen.com 